\title{
EL INTERNACIONALISMO, LA SOLIDARIDAD Y EL INTERÉS MUTUO: ENCUENTROS ENTRE CUBANOS, AFRICANOS, Y ALEMANES DE LA RDA
}

O internacionalismo, a solidariedade e o interesse mútuo: encontros entre cubanos, africanos e alemães da RDA Internationalism, solidarity and mutual interest: encounters between Cubans, Africans and GDR Germans

BERTHOLD UNFRIED Y CLAUDIA MARTÍNEZ

http://dx.doi.org/10.1590/\$2178-14942017000200007

Berthold Unfried es profesor asociado del Instituto de Investigaciones de Historia Económica y Social de la Universidad de Viena, Austria (berthold.unfried@univie.ac.at).

Claudia Martínez es licenciada en Relaciones Internacionales de la Universidad de La Habana, Cuba (martinezhernandezclaudia@gmail.com).

Artículo recibido el 1 de febrero del 2017 y aprobado para publicación el 4 de mayo del 2017. 


\title{
RESUMEN
}

La asistencia militar cubana en Angola y Etiopía es muy conocida en el ámbito internacional. Sin embargo, la historia de la asistencia civil aún no ha sido escrita en toda su magnitud. Esta contribución esboza una comparación entre el "internacionalismo" cubano y el sector de la "solidaridad" o "ayuda socialista" de la República Democrática Alemana (RDA). ¿Qué significaron y cuáles fueron las terminologías y prácticas correspondientes de los alemanes? ¿Qué tipos de internacionalismo y solidaridad de práctica pueden identificarse? ¿Cómo fueron las relaciones entre cubanos y alemanes con sus contrapartes etíopes y angolanos y con el pueblo de esos países y qué se transfirió en ese encuentro triangular? La contribución se basa en material de los archivos cubanos y alemanes, así como en entrevistas.

Palabras ClaVe: internacionalismo; solidaridad internacional; Cuba; RDA; Angola; Etiopía.

\section{RESUMO}

A assistência militar cubana em Angola e na Etiópia é muito conhecida no âmbito internacional. No entanto, a história da assistência civil ainda não foi escrita em toda a sua magnitude. Esta contribuição esboça uma comparação entre o "internacionalismo" cubano e o setor da "solidariedade" ou "ajuda socialista" da República Democrática Alemã (RDA). 0 que significaram e quais foram as terminologias e práticas correspondentes dos alemães? Que tipos de internacionalismo e solidariedade de prática podem ser identificados? Como foram as relações entre cubanos e alemães com suas contrapartes etíopes e angolanas e com o povo desses países e o que se transferiu nesse encontro triangular? A contribuição se baseia em material de arquivos cubanos e alemães, assim como em entrevistas.

Palavras-ChaVE: internacionalismo; solidariedade internacional; Cuba; RDA; Angola; Etiópia.

\begin{abstract}
Cuban military assistance in Angola and Ethiopia is reasonably well known internationally. However, Cuban civil assistance has not yet been researched in its full dimension. This article compares Cuban 'internationalism' and the 'solidarity' or 'socialist aid' sector of the GDR. What did they mean and what were the corresponding German terminologies and practices? What kinds of internationalism and solidarity practices can be identified? What were relations like between Cubans and Germans and their Ethiopian and Angolan counterparts and with the people from those countries? Finally, what was transferred in that triangular encounter? This article is based on Cuban and German archives, as well as interviews.
\end{abstract}

KeYwORDS: internationalism; international solidarity; Cuba; GDR; Angola; Ethiopia. 
a asistencia militar cubana a los países africanos es bien conocida en el ámbito internacional, debido fundamentalmente al trabajo de Piero Gleijeses, así como al de otros autores, muchos de los cuales fueron protagonistas de aquellas misiones. Las investigaciones sobre la asistencia civil, por su parte, son más recientes y han revelado dimensiones inesperadas, sobre todo en Angola.

En la década de 1980, Cuba era el país con el más alto porcentaje de ciudadanos enviados en misión "internacionalista" civil (Erisman, 1991: 140; Feinsilver, 2010: 87-88). Casi un tercio de los delegados a los congresos del PCC de 1980 y 1986 habían cumplido (según Domínguez, 1989: 281) misiones fuera de la Isla. Ese ciclo cubano de proyección internacionalista no cuenta aún con una historiografía adecuada a su importancia. "Cuba... que nunca ha querido escribir sobre esto... está hoy dispuesta a prestar su modesta cooperación, abriendo progresivamente sus archivos y documentos", afirmó Fidel Castro en el 2006 (Ramonet, 2006: 377). ${ }^{1}$ Se conoce que entre 5.000 y 12.000 soldados cubanos (Gleijeses, 2013: 324, por la cifra máxima) lucharon con armas soviéticas y alemanas para salvar la revolución etíope en la crítica fase de la invasión somalí durante el verano y el otoño de 1977. Sin embargo, internacionalmente se sabe muy poco sobre los 500 a 900 trabajadores civiles cubanos presentes en Etiopía (Gleijeses, 2013: 326, por la cifra inferior en mediados de la década de 1980).

Tanto en Angola como en Etiopía, los cubanos apoyaron procesos de formación de un Estado y una sociedad nuevos. Desde esa perspectiva surge el carácter político de la asistencia cubana. Sin obviar el objetivo de ayudar en momentos coyunturales a países que, independientemente de su sistema político, necesitaron del concurso cubano y donde prevaleció el puro aspecto humanitario, en esta contribución abordaremos situaciones de compromiso de larga duración en todos los planos, tanto militar ${ }^{2}$ como civil en varios niveles.

\section{LA TERMINOLOGÍA Y LOS CONCEPTOS}

¿Qué se puede entender por "internacionalismo cubano" y "internacionalismo"?

"Internacionalismo cubano" se emplea para denominar el servicio de cubanos en países de África, América Latina y Asia en sus dos aristas: la militar, en la cual se nota la referencia a las brigadas internacionales en la guerra civil española, y la civil. Reconocido como 
un principio esencial dentro de la política de Cuba revolucionaria, es un concepto vinculado con sacrificio, abnegación y solidaridad desinteresada 3 y, por tanto, un concepto altamente normativo con motivo dominante político-moral. La idea es que representa la práctica solidaria en su nivel más alto, incluso como un gesto de reciprocidad por la solidaridad recibida de hombres y mujeres desde otras partes del mundo. Con la misión internacionalista cubana, se alcanzó "el peldaño más alto de la especie humana", así lo exprima una internacionalista (Martín González, 2015). Hubo mucha abnegación y privación de parte de los internacionalistas cubanos, para quienes la misión no poseía incentivos materiales relevantes. También hay que recordar que el internacionalismo cubano en Angola y Etiopía fue concebido como parte de una aspiración de liberación "antiimperialista" en los tres continentes.

Habida cuenta del objeto histórico de nuestro trabajo, distinguimos dos formas fundamentales de internacionalismo cubano a partir del triunfo de la Revolución en 1959. La primera de ellas acabaría en principios de la década de 1990 con el colapso del sistema socialista en Europa, mientras que la segunda forma se mantuvo, ya sea pagada o gratuita. Con más de medio siglo de historia, el "internacionalismo cubano" se puede periodizar, grosso modo, de la manera siguiente:

- Una primera etapa tercermundista y guerrillera del "internacionalismo cubano" marcada por la solidaridad revolucionaria tricontinental, que se inició en 1959 y se extendió hasta cerca de 1970. Así surgió la Organización de Solidaridad de los Pueblos de África, Asia y América Latina (OSPAAAL), que en enero de 1966 fundó comités de apoyo a movimientos de liberación. La OSPAAAL fue concebida como una organización internacional de los tres continentes, Cuba como vanguardia de esa nueva organización internacional del tercero mundo. En aquella etapa empezó también la ayuda civil: en 1963, si interpretamos la primera brigada médica cubana en Argelia como inicio de la colaboración civil.

- 1975-1991 (fechas establecidas por la epopeya angolana): ciclo de inserción del "internacionalismo cubano" en el sistema socialista a partir del ingreso de Cuba en el CAME. El ingreso de Cuba en el CAME 1972 como segundo país extraeuropeo (después de Mongolia y antes de Vietnam) cambió profundamente la política económica y las instituciones del país. Como plataforma de comunicación entre los países socialistas europeos y los países subdesarrollados en el sistema socialista, Cuba experimentó un apogeo de su presencia mundial. En este periodo se evidencia la intervención cubana en procesos como la construcción de un Estado después de la independencia de Guinea-Bissau y sobre todo de Angola, la guerra interna y con la intervención sudafricana, que resultó en la independencia de Namibia, así como la intervención en Etiopía, que salvó la revolución etíope. 
Actor principal en esa etapa del "internacionalismo cubano", el Estado cubano envió miles de internacionalistas para asistir a la construcción de un Estado en Angola, en Guinea-Bisáu, y para reforzar la revolución etíope. La coyuntura internacional era una nueva fase de expansión del sistema socialista mundial en los tres continentes. El sistema socialista mundial pareció marchar adelante: en 1975 victoria en Vietnam; en 1975 victoria de los movimientos de liberación progresistas en Angola y Mozambique; no olvidemos a Guinea-Bisáu y Yemen; la revolución en Etiopía; y en 1979 en Nicaragua. A mediados de la década de 1970, vemos a Cuba en ofensiva en África. Cuba actuó por iniciativa propia (como lo demuestra Gleijeses en sus libros), aunque en el marco del sistema socialista mundial. La Unión Soviética, que ya priorizó una política de détente sobre una política de cambio revolucionario en el mundo, no siempre estuvo de acuerdo con esas iniciativas.

- Década de 1990 hasta la actualidad: ciclo humanitario y de trueque, que se caracteriza por la asistencia humanitaria de emergencia y las experiencias de un internacionalismo "de beneficio mutuo" que consiste en la exportación de servicios cubanos, sobre todo en el sector de la salud. Las raíces se encuentran en las etapas anteriores; pero el sentido, la política general ahora son diferentes.

Por otra parte, el "internacionalismo" en un sentido más amplio, incluyendo la experiencia cubana, puede entenderse como una manera de estar o vivir traspasando el Estado nacional, como práctica de vida internacionalista, cosmopolita, mundial; en otras palabras, tener la experiencia de diversas partes del mundo, tener al mundo como esfera de acción y como fuente de experiencia vital. Es de suponer que esa experiencia marcara a las personas y constituyera la creación de una identidad común. Aquí se abre un área de comparación entre sistemas e ideologías políticas a partir de grupos de personas que practican un estilo de vida itinerante a través del mundo o en un espacio transnacional. Claro que esa visión abre un marco de comparación mucho más grande, diferente del que se abre en la visión política. Un marco de comparación que comprendería también otras experiencias, como, por ejemplo, al personal de la "ayuda al desarrollo" occidental.

Un primer marco de comparación, de la RDA y Cuba o Etiopía y Angola, sería la cooperación entre países profundamente desiguales en el mundo socialista; mientras que el segundo marco, aún más amplio, incluiría las formas internacionalistas de acción y sus maneras de estar en el mundo. Un efecto de tal comparación sería insertar la propia experiencia del internacionalismo cubano en una historia global comparada, de internacionalismos.

Veamos ahora los casos de la RDA y Cuba en Etiopía y Angola, que se insertan dentro del segundo ciclo esbozado de "internacionalismo cubano", así como dentro de los dos campos de comparación presentados anteriormente. Para ello tendremos en cuenta las 
terminologías empleadas y sus prácticas correspondientes, los tipos de internacionalismo y solidaridad, así como las relaciones entre las partes implicadas.

\section{RDA: "SOLIDARIDAD" Y RELACIONES ECONÓMICAS EN EL "INTERÉS MUTUO"}

as relaciones de la RDA con los países africanos en el marco de "un camino de desar-
rollo socialista", específicamente con Etiopía, Angola y Mozambique en los años 1970 y
1980, consistieron, grosso modo, en dos elementos diferentes.
El primero fue el desarrollo de relaciones económicas en el orden del interés y beneficio mutuo. Cercano al comercio exterior, este tipo de comercio trataba de cambiar su naturaleza para alejarse de los intereses capitalistas que originaron la desigualdad en el mundo. Se buscaba ser justo mediante una suerte de ayuda a través del comercio. Esta estrategia formaría parte de una división internacional socialista del trabajo que condujera a una forma socialista o, por lo menos, no capitalista de desarrollo.

El segundo elemento fue la concepción de estas relaciones como una forma de solidaridad internacional, un concepto de la esfera política en que el interés material no era un fin en sí mismo, sino un medio para lograr fines geopolíticos más amplios.

En resumen, existió una línea de relaciones económicas con intereses y beneficios mutuos, otra de cooperación científico-técnica con condiciones ventajosas y, como tercera línea, se encontraban las transferencias de "solidaridad" de forma gratuita.

Las interacciones de la RDA con Etiopía fueron una mezcla de actividades comerciales complementadas por interacciones que contenían, en mayor o menor medida, el elemento de la subvención. Así se produjo la construcción de infraestructura y fábricas financiadas por préstamos suaves (de gobierno), el envío de expertos desde la RDA, el entrenamiento de personal etíope y - siempre de forma gratuita - el envío de "Brigadas de la Amistad" integradas por jóvenes de la organización de la "Juventud Libre Alemana" (FDJ, por sus siglas en alemán) de la RDA para trabajos de reparación, equipos hospitalarios y (a largo plazo) de armas. El interés mutuo o el beneficio mutuo en el intercambio comercial, la complementación para la cooperación científico-técnica y la solidaridad crearon una suerte de programa integrado para el desarrollo de los países.

La mutualidad o reciprocidad pudieron tomar la forma de convergencia política o de comercio de trueque (barter trade). Con su política de "solidaridad", la RDA pudo obtener un beneficio en legitimidad política, sobre todo frente a la RFA. Recordemos que África fue un 
escenario más de la Guerra Fría. En las relaciones comerciales, la RDA pudo obtener café en trueque sin gastar moneda convertible en el mercado mundial.

Solidaridad y beneficio mutuo no eran excludentes, la primera era la condición de la segunda. Esa fue la fórmula general encontrada por los alemanes en el caso de sus relaciones con Cuba y reanudada luego con Etiopía. Al referirse a la organización de partido de los cooperantes de la RDA de La Habana: "Mientras ayudamos a Cuba para establecer capacidades de producción, substitución de importaciones, fortalecimiento de la capacidad de exportación, aumento del producto nacional, desarrollo del socialismo, también la empoderamos para cumplir a través de sus exportaciones el compromiso hacia la RDA."4

\section{CUBA: "INTERNACIONALISMO CUBANO" Y "AYUDA DESINTERESADA"}

E n el marco de su segundo ciclo de proyección "internacionalista", Cuba respondió al Ilamado del Movimiento Popular de Liberación de Angola (MPLA), en 1975, y del gobierno revolucionario de Mengistu Haile Mariam en Etiopía, en 1977. En el caso cubano, se hablaba de "ayuda desinteresada" que significaba la ausencia del interés unilateral en el sentido económico. Eso se evidencia incluso en las conclusiones de analistas contemporáneos cubanos observadores desde Estados Unidos. ${ }^{5}$ Pero la noción de "interés" no debe ser entendida tan solo en el sentido económico. En países socialistas, la tendencia era la subordinación de la economía a la política y no lo contrario. En todo caso se podría hablar de un interés político a largo plazo que todo esfuerzo de desarrollo (o de revolución) comparte. El interés político cubano era contribuir al avance de la sociedad etíope por el camino hacia el socialismo como hicieron los países socialistas europeos con respecto a Cuba ${ }^{6}$ para reanudar a largo plazo esa experiencia cubana. En una perspectiva más amplia, contrarrestar la hegemonía estadounidense y contribuir a avanzar en la senda hacia un sistema socialista mundial.

En este punto es conveniente recordar diferencias y cercanías entre los conceptos de ayuda, solidaridad y cooperación en términos de mutualidad.

Ayuda: este concepto supone una asistencia unilateral en el sentido del oferente hacia el receptor.

En el caso de la noción de solidaridad existe una mutualidad: ser solidario supone que ambas partes se aprovecharán a largo plazo de la relación solidaria y que existe una responsabilidad de una parte hacia la otra, por motivos culturales, históricos o ideológicos. Esa era la idea inicial del "internacionalismo proletario", basada en una suposición de igualdad de intereses entre los obreros, que hace de ellos una clase social internacional. Sin embargo, ante la constatación de una realidad de diferencia profunda en lo relativo a las condiciones sociales 
e intereses, la solidaridad de reciprocidad fue sustituida posteriormente por una idea política de "solidaridad antiimperialista". Del mismo modo, el concepto de mutualidad fue sustituido por un significado de solidaridad como flujo de recursos univectorial. Entra la idea de que Cuba con su "ayuda solidaria" liquidó una "deuda con la humanidad" que había resultado de la transferencia de esclavos desde África (García Márquez, 1977), sustituida más tarde por la idea que "Cuba, a la vez que recibía asistencia en sus relaciones económicas con los países socialistas más desarrollados, consideró suyo el deber de ayudar a los países más pobres" .

Cooperación: este término supone una mutualidad de flujos y de intereses mediatizados entre ambas partes.

¿Dónde estuvo la mutualidad (el interés mutuo) en las relaciones cubano-africanas?

La diferenciación se complica por el hecho de que tanto Cuba como la RDA Ilamaron "ayuda solidaria" a la transferencia gratuita de recursos. En la esfera "solidaria" no hubo mutualidad de flujos económicos, esas prestaciones eran gratuitas. El "internacionalismo solidario" de Cuba tuvo también tal sentido. En Etiopía, la ayuda civil cubana era gratuita, lo que resultaba embarazoso para los alemanes de la RDA, que temían quedar en una situación difícil porque trataron de cobrar sus servicios de cooperantes, lo que lograron solo parcialmente en la práctica. ${ }^{8}$

El envío de cooperantes no tuvo un interés pero tuvo un aspecto económico para Cuba. Claro que la Isla no pudo concurrir sola a los gastos de miles de cooperantes durante un espacio de tiempo tan largo como en el caso de Angola. Los países capaces de hacerlo tuvieron que compartir los gastos, así se puede leer en la revista Colaboración Internacional. En 1982, el director de Cubatécnica hablaba de "dos vertientes esenciales: la colaboración gratuita y la compensada. La primera se ofrece a los países pobres y subdesarrollados... y la segunda a las naciones que poseen una situación económica estable y favorable" (Colaboración internacional, 1982: 14). Esto también se recogió en las propias palabras de Fidel Castro a Agostinho Neto en el año 1979. ${ }^{9}$ En el caso de Angola, a partir de un acuerdo de noviembre de 1977, la ayuda civil era pagada (Gleijeses, 2013: 82-84) y coincidía en ese mismo tiempo con el inicio del capítulo etíope y con las dudas por parte de la dirección cubana que temía un sobredimensionamiento cubano en África. Angola tenía recursos en divisas provenientes de la exportación de petróleo y café por lo que fue calificada como un país capaz de concurrir a los gastos de la ayuda cubana, tomando así dicha ayuda un aspecto de cooperación. Tras la salida de los portugueses, cuando Angola se quedó sin expertos, los cubanos aseguraron la cosecha y el transporte del café y protegieron la extracción petrolera en Cabinda, los dos productos de exportación esenciales de Angola. Eso ocasionó relaciones triangulares con la RDA que también había enviado asesores y especialistas a Angola y establecido un intercambio comercial 
con importaciones de café y petróleo. ${ }^{10} \mathrm{~A}$ la vez, la RDA se enlazó estrechamente en todos los planos con Cuba.

Además, el acuerdo de noviembre de 1977 tuvo un efecto de regulación del pedido de pago que Fidel Castro esperaba recibir por esa medida. Vale la pena mencionar por extenso sus palabras a Neto al plantear el cuadro y la lógica de la asistencia cubana:

También la gente tiene una tendencia a pedir técnicos, yo lo sé. [...] Entonces el problema es ver cuáles son los imprescindibles [...] Y yo lo digo por nuestra experiencia, porque a la gente le gusta pedir y pedir. En ese sentido, yo creo que es mejor que los tengan que pagar; porque si tienen todos los técnicos gratuitos, todo el mundo va a pedir 20.000,30.000, mientras que cuando ven que eso tiene una connotación económica y tiene una carga económica y un peso económico, la gente va a pedir menos. Ustedes deben pedir el mínimo de técnicos. [...] Vaya, no nos arruinamos por decir que hay 800 técnicos en Angola, médicos, lo que sea, trabajando gratuitamente, como los tenemos en todos los demás países. En todos los demás países africanos, quitando los países ricos, petroleros, la asistencia nuestra es gratuita. El único país que da la asistencia técnica gratuita somos nosotros. Ahora, si nos piden 10.000 , nosotros no podemos darlos gratuitamente, compañero Neto. Yo quisiera que usted entendiera ese problema. Y el día que sean menos de 1.000, bueno, nosotros en Etiopía vamos a tener cerca de 1.000, es gratuito, y en Mozambique tenemos cerca de 600, más o menos vamos a tener, es gratuito, médicos y todo gratuito; en Sao Tomé tenemos más de 100, yo diría que cada 800 habitantes de Sao Tomé hay un Cubano allí, es gratuito. Y en Guinea Bisáu, el Congo y Tanzania, en todos los países de África nuestros técnicos son gratuitos, en todos. Ahora, en Angola son miles, no podemos. ${ }^{11}$

Y, como resumen: "Una forma en que se manifiesta la obligación internacionalista de Angola es dependiendo lo menos posible de la colaboración de Cuba". Como compromiso entre las posibilidades económicas angolanas y los gastos cubanos, Fidel propuso el envío de voluntarios pregraduados, los destacamentos pedagógicos, pagados por Cuba. ${ }^{12}$

El reglamento de noviembre de 1977 tuvo como efecto la reducción del número de cooperantes cubanos de 7.000 a 4.000 y su limitación a lo necesario. En su lugar, el gobierno angolano aumentó el número de cooperantes occidentales, sobre todo portugueses. ${ }^{13}$ La compensación del gobierno angolano debía ser en divisas (dólares) lo que se suspendió en 1983. El presidente Dos Santos agradeció a Fidel Castro por la cooperación civil gratuita a partir del primero de octubre de 1983 y se comprometió a pagar el transporte aéreo, el abastecimiento y el alojamiento de los internacionalistas cubanos. ${ }^{14} \mathrm{~A}$ pesar de ese compromiso, la ayuda a Angola fue pagada solamente entre 1978 y 1983. Jorge Risquet, el jefe de la administración civil cubana en Angola, calculó que eso reglamento hizo perder alrededor de 20 millones de dólares anuales a Cuba (Gleijeses, 2006: 23). 
El hecho de que a finales de la década de 1970 y principios de la década de 1980 se iniciara el pago de los servicios cubanos por algunos países, se situaba también en el contexto de una política de exportación en el marco del primer plan quinquenal cubano (1976-1980) y en la coyuntura de una política general de los países del CAME que tenían que restructurar profundamente las relaciones con los países de África en la perspectiva de más mutualidad de flujos económicos. Esto se observaba de manera muy clara en la RDA, donde se creó, en 1977, la Comisión del Comité Central del Partido Socialista Unificado de Alemania encargada de las relaciones con África, Asia y América Latina en la década de 1980 bajo la dirección del sector económico. En Cuba se hablaba de "exportaciones de servicios técnicos" (Roca 1978: 172, citando Bohemia 15.9.1978) como término homólogo de "exportaciones inmateriales". Sobre ellas trató de concentrarse la RDA en sus relaciones con países africanos en la década de 1980 (Unfried, 2012: 80). El acuerdo de noviembre de 1977 se insertó en ese esfuerzo de exportación de servicios que fue el origen de la actual política de exportación de servicios médicos, que caracteriza la tercera etapa del internacionalismo cubano, según el país de destino, de forma gratuita o compensada. A partir de una cierta magnitud alcanzada, por ejemplo, en Angola, con miles de cooperantes durante un espacio de tiempo largo, los países que por sus recursos podían hacerlo, tuvieron que concurrir al gasto (Gleijeses, 2013: 327).

Entonces, el "internacionalismo cubano" tuvo un nivel de solidaridad sin reflujos económicos y un elemento de intercambio económico, en que la mutualidad era también económica. Sin esa base económica, la carga no hubiera sido sostenible a largo plazo.

\section{LA CONSTRUCCIÓN ORGANIZATIVA}

\section{RDA}

$\mathrm{E}$ ncontramos actores divergentes en este campo: por la autoridad económica de la RDA, Günter Mittag y la coordinadora comercial (Kommerzielle Koordinierung/Koko), con su director, Alexander Schalck-Golodkowski, quien fue parte de la dirección de la Comisión del Comité Central del Partido Socialista Unificado de Alemania encargada de las relaciones con África, Asia y América Latina en los 80, cuya tarea principal fue movilizar o ahorrar divisas para el comercio donde fuera posible, desde el Departamento de Relaciones Internacionales del Partido hasta el propio secretario general, quien demostró gran interés personal en la política de solidaridad como una forma especial de relaciones internacionales y como una forma original de diplomacia no convencional. Las relaciones entre estos actores del comercio exterior 
en "el interés mutuo" y de la política de solidaridad no ocurrieron sin tensiones creadas por divergencias de intereses políticos y económicos, que generaron ciertos conflictos.

\section{Cuba}

finales de la década de 1970, en el marco del primer plan quinquenal, se instauraron
el "Comité Estatal de Colaboración Económica" (CECE) y la Agencia de Implementación y Logística "Cubatécnica", según Noemí Benítez de Mendoza, jefa del Departamento de Exportación de Asistencia Técnica y Desarrollo Industrial del Centro de Asistencia Técnica. Encargado de la coordinación de las relaciones económicas y científico-técnicas bilaterales, el CECE tuvo un papel central en la implementación del internacionalismo civil cubano, por ejemplo, en la atención al personal. ${ }^{15}$ Hacia 1982 el director de Cubatécnica hablaba de alrededor de "25.000 compañeros en el exterior" (incluyendo a los jóvenes trabajadores en formación) y de un papel de la agencia de "seleccionar al personal" (Colaboración Internacional, 1982: 14-16).

Esa estructuración integró el "internacionalismo" civil cubano en el cuadro de la "colaboración". Así nació una estructura marcada por una terminología de "colaboración", colaboración con los países socialistas europeos por un lado, y colaboración con los países de AAAL por otro lado.

Así como en la RDA, existía una diferenciación entre colaboración económica, colaboración científico-técnica y el sector propio "internacionalista" o, como lo llamaron los alemanes, de "solidaridad" de prestaciones que eran unilaterales teniendo en cuenta las asimetrías económicas de la contraparte. Este último sector fue marcado por una motivación con dominación política (y no económica). Los enviados no recibían mucho más que sus salarios cubanos y se les garantizaba su puesto laboral en Cuba. Al regresar, recibían la medalla de trabajador internacionalista como signo de distinción.

En el sector comercial entre Cuba y Etiopía existían protocolos de trueque. ${ }^{16}$ Así nació un sector comercial de relaciones con los países africanos. Este sector comercial consistió en la exportación de servicios técnicos cubanos en los sectores de sistemas de salud y educación, producción azucarera, construcción e infraestructura agrícola; era de tamaño aparentemente muy limitado, por medio de un comercio de trueque (Colaboración Internacional, 1985: 22).

También encontramos al Partido como actor decisivo. La relación entre el Partido, las diferentes estructuras de dirección y los departamentos de relaciones internacionales impactaba en la decisión a nivel ministerial para la selección y movilización del personal especializado. En el caso cubano está claro que las decisiones más importantes relacionadas con el número, 
el tipo de especialistas y la duración de la misión se discutía al más alto nivel, entiéndase la alta dirección del Partido, que coincidía con la del Estado y el Gobierno.

Una vez acordados los términos se empleaban las estructuras creadas para seleccionar y movilizar a las personas bajo el criterio de la voluntariedad. Eso dotó al país de un sistema establecido a finales de la década de 1970 para agilizar todo el proceso. El entramado institucional creado se trasladaba, con el apoyo del personal diplomático cubano, en versiones simplificadas de acuerdo con las características del terreno a los países receptores para organizar, dirigir y controlar las tareas de los cooperantes.

Durante los años en que Antonio Pérez se desempeñó como embajador cubano en Etiopía recuerda que en Addis Abeba estaba la Embajada y había una oficina de colaboración (CECE y Cubatécnica) que respondía ante el embajador, rendía cuentas, presentaba informes, realizaba un trabajo conjunto, atendía los problemas del trabajo, problemas de conductas, en fin, todas las variadas cuestiones que podían presentarse en la práctica. Además, había una organización del Partido que visitaba a los colaboradores y se reunía con los núcleos formados en todos los casos en los que igualaban o superaban el número de 3 militantes. ${ }^{17}$ Como parte de la estrategia cubana, los internacionalistas trasladaron consigo los arreglos de la vida social y política, incluidas las estructuras partidistas.

\section{El CUADRo DE LOS EVENTOS EN ETIOPÍA}

a participación cubana en Angola está, gracias particularmente a los trabajos de Glei-
jeses, muy bien conocida. No ocurre lo mismo para la segunda gran incursión cubana en África durante las décadas de 1970 y 1980. El capítulo etíope tiene que verse junto a la ofensiva cubana en África a mediados de la década de 1970, que comenzó por Angola como parte de la continuidad de una política en favor de los movimientos de liberación nacional (Angola, Mozambique) y de los procesos revolucionarios (Etiopía).

Inicialmente estimulado por Werner Lamberz, un dirigente carismático del partido alemán encargado de las relaciones con África y que tuvo grandes proyectos de cooperación económica triangular RDA-Etiopía-Libia, ${ }^{18}$ fue el líder de la revolución cubana quien actuó como intermediario entre Etiopía y los países socialistas y quien despertó el interés de las autoridades de la RDA por vincularse a la revolución etíope. En la crisis del otoño de 1977, cuando las tropas de Somalia se acercaron a Addis Abeba, y la caída del régimen era un peligro inminente, Mengistu acudió primero a Cuba, luego a Moscú y a Berlín Oriental. Rápidamente cubanos, soviéticos y alemanes de la RDA asistieron al salvamento del "experimento socialista etíope". Los soldados cubanos lucharon con equipo soviético y alemán. Esta dramática secuencia está 
diariamente documentada en telegramas enviados al Partido y al Estado de la RDA por su embajador. ${ }^{19}$ La revolución etíope estaba cercada y en peligro, Mengistu escribió a Honecker poco después de asumir un incontestado liderazgo tras la eliminación de Teferi Bentu y sus compañeros en febrero de 1977. Fue el deber internacionalista de los estados socialistas asegurar el éxito de la lucha de esta importante parte de la liga antimperialista mundial. ${ }^{20}$ Fidel conoció a Mengistu en marzo de 1977. Los dos líderes parecían entenderse. Su relación fue descrita como "extraordinariamente cordial y marcada por una profunda amistad" . ${ }^{21}$ Un informe cubano de inteligencia concluyó que ellos tenían que ver con una revolución real: "Se ha realizado una revolución en Etiopía", y propone una serie de medidas de intervención: ayuda militar y de seguridad agregada de "ayuda y cooperación" y "asistencia técnica". ${ }^{22}$ De acuerdo con Piero Gleijeses, quien en su nuevo libro basado en fuentes cubanas menciona el episodio etíope de pasada, Fidel Castro desde el inicio conocía del sobredimensionamiento de las capacidades cubanas en África: "no parecía posible que un pequeño país como Cuba pudiera mantener dos importantes misiones en África" (Gleijeses, 2013: 45). Entonces, tomó la decisión de intervenir tres meses después de la primera petición etíope. Un alto oficial de relaciones internacionales del Partido Socialista Unificado de Alemania recuerda que fue Lamberz quien convenció a Fidel, con quien tenía buenas relaciones personales, a entrar en Etiopía (entrevista a Friedel Trappen, en Döring, 1999: 282). En cualquier caso, parece ser que una fuerte relación triangular de cooperación Etiopía-Cuba-RDA fue crucial en el caso etíope. Por supuesto, la URSS y su apoyo fueron esenciales, aunque este último país no parece haber tenido la iniciativa.

\section{SituACión De LOS COOPERANTES}

E n un corto periodo de tiempo, entre 1977 y 1978, el número del personal de la RDA en Etiopía saltó de una docena a 300 para alcanzar el máximo de 450 (incluyendo a los familiares) en 1986. El entonces embajador de la RDA recuerda ese periodo como el más estresante de su vida: la estructura organizacional para recibir a esas personas tiene que ser establecida, hay que darles casa y tomar todas las medidas de seguridad necesarias. ${ }^{23}$

Simultáneamente, la cooperación cubana atendía casi al doble de personas. Esta ventaja cubana podría estar vinculada a una mayor experiencia de transferencia de miles de cooperantes en el caso angolano, a una flexibilidad y una atención simplificadas (más fácil) al personal cubano que iba sin familia a diferencia de los alemanes. De cualquier forma los testimonios de cubanos parecen más felices en situaciones potencialmente más estresantes por sus características. 
¿Quiénes eran esas personas?

En el caso de la RDA:

- Algunos oficiales de la Comisión Central de Planificación.

- Asesores del Gobierno que trabajaban en las oficinas del Gobierno etíope.

- Algunos asesores del Partido que ayudaban en la fundación del Partido Marxista-Leninista (el COPWE) como estructura dirigente central.

- Algunos asesores de seguridad que ayudaban y entrenaban al personal de seguridad etíope, así como garantizaban la seguridad de los alemanes y procuraban información.

- Una amplia gama de especialistas, usualmente llamados "kooperanten": desde profesores universitarios y de escuelas secundarias, formadores de maestros, doctores y geólogos hasta ingenieros y mecánicos.

- "Brigadas de la Amistad": miembros de FDJ (homólogo de UJC) quienes supuestamente deberían trabajar en una atmósfera de amistad internacionalista que los uniera a los locales. Sus actividades fueron parte de las prestaciones de la solidaridad gratuita.

De la parte cubana:

- Asesores (en los ministerios).

- Seguridad e Inteligencia.

- Médicos, enfermeras y otros profesionales de la Salud.

- Profesores y docentes universitarios.

- Formadores de maestros.

- Especialistas con tareas ejecutivas mandados por los ministerios: maestros, trabajadores especializados, por ejemplo para la construcción de la fábrica de cemento Mugher 0 de carreteras.

- Destacamentos pedagógicos internacionalistas formados por estudiantes pregraduados, empezando por los destacamentos pedagógicos internacionalistas Che Guevara en Angola a partir de 1978. Esos destacamentos fueron el homólogo de las Brigadas de la Amistad de la "Juventud Libre Alemana" (FDJ) en la RDA.

Desde julio de 1977, hasta 1.000 trabajadores civiles cubanos estuvieron presentes en Etiopía (Colaboración Internacional, 1/1980). Según la prensa cubana, en 1979, un cuarto de los médicos en Etiopía eran cubanos, la mitad de los cubanos trabajaba en la salud. ${ }^{24}$ Había como en Angola un jefe de la asistencia civil cubana, Raúl Curbelo, designado en noviembre de 1979.25 Fueron enviados, como era usual, doctores y enfermeras, profesores y trabajadores 
de la construcción. En la fábrica de cemento New Mugher trabajaron 200 montadores cubanos junto con 27 ingenieros de la RDA y 4.000 trabajadores etíopes, con un objetivo de formación del personal etíope, que reanudó la colaboración germano-cubana para la construcción de la empresa de cemento en Cienfuegos. ${ }^{26}$ En la dirección contraria, entre 1978 y 1994 casi 3.000 etíopes realizaron sus estudios en Cuba (Gleijeses, 2013: 326).

\section{LAS RELACIONES CON LA CONTRAPARTE}

\section{RDA}

L as relaciones con la contraparte eran siempre un tema sensible. En primer lugar, había que en situación de conflicto se favorecía la asunción de una falta por parte del alemán. ${ }^{27}$ No disponemos de ejemplos cubanos, pero podríamos formular la hipótesis de que no era diferente en este caso. La atmósfera de los testimonios lo deja suponer.

La experiencia de la RDA en la cooperación decidida en alto nivel encontró obstáculos en la implementación por actores etíopes hostiles al gobierno. La "Etiopía socialista" era un Estado muy diferente políticamente de otros países socialistas como la RDA (Unfried, 2016). De acuerdo con testimonios de la RDA, el entonces embajador cubano Antonio Pérez recuerda que los estudiantes etíopes recién llegados de Cuba a su país presentaron problemas para su inserción laboral y en algunos casos los puestos que les fueron asignados no eran equivalentes a su formación. ${ }^{28}$ Eso ocurría, en ocasiones, debido a los obstáculos creados deliberadamente por la oposición de sectores del aparato estatal etíope, en desacuerdo con la política del gobierno de Mengistu.

\section{CUBA}

U na primera explicación a la asimilación cubana en Etiopía podría plantear que un sector de la contraparte fue formado fundamentalmente por la Isla de la Juventud, en que no solo obtuvieron una formación cognitiva, sino también las referencias político-culturales para entenderse con sus homólogos cubanos. Así se construyó una esfera de cooperación con puntos de referencia compartidos y como parte de un largo programa de desarrollo integral.

Sin embargo, en segundo lugar, se debe reflexionar sobre el hecho de que cuando los primeros cubanos llegaron a Etiopía, no había estudiantes regresados de Cuba, entonces era evidente la existencia de elementos anteriores a la sinergia creada en las escuelas cubanas. ${ }^{29}$ 
Para muchos, la solución radica en el componente histórico africano presente en la composición étnica cubana. Pero dicho componente era un pasado lejano, más imaginado que vivido. Quizás fue más importante en Angola, donde parecía haber una identidad "negra" más claramente distinguida de la mestiza o mulata que en Etiopía, donde los cheles amáricos (de piel clara) eran la capa dominante que miraba con superioridad a los negros Oromos.

Una tercera posición encontrada en los testimonios defiende que lo especial en el caso de los cubanos en Etiopía fue que comenzaron por una cooperación anterior, la militar, y continuaron hacia una forma diferente, la civil. ${ }^{30}$ Podemos dar por sentado que los cubanos fueron mejor integrados que los alemanes.

\section{LAS RELACIONES CON LA POBLACIÓN}

L os internacionalistas cubanos habitualmente vivieron en viviendas comunes (predios) niones políticas, los informes de trabajo, las evaluaciones en el colectivo, las decisiones en los casos de indisciplina, la vida cotidiana hasta - en el caso angolano - la comida que llegaba de Cuba. Eso creó un espacio de vida propia cubana en países como Angola y Etiopía, enclaves cubanos en la zona de asignación donde las personas pudieron recrear, en mayor o menor medida, una dinámica de vida cubana en condiciones diferentes. Esos enclaves cubanos tuvieron un intercambio limitado con la población alrededor. Ellos facilitaron la transferencia de cubanos de la Isla hacia esas microsociedades donde pudieron vivir una vida cubana en África. Los contactos no organizados fueron limitados, incluso restringidos al mínimo necesario por una visión realista de los peligros potenciales, no solo por causas de seguridad en una situación de guerra donde el enemigo no se conoce; sino también por problemas que surgen fácilmente en esas situaciones de contacto como el intercambio en forma de tráfico ilícito y prostitución. Sin embargo, en casos cuando cubanos y alemanes trabajaron juntos en Etiopía, hay varios testimonios según los cuales los cubanos tenían relaciones más fáciles con la gente local. Hay que decir que los alemanes tuvieron un tiempo difícil en Etiopía: la experiencia de los cooperantes alemanes en Cuba, donde la mayoría se sentía bienvenida, fue diferente a su acogida en Etiopía.

Parece que la norma de limitación de contactos con personas de países no socialistas no estaba en todos casos aplicada estrictamente, por lo menos en situaciones en que los cubanos no vivían concentrados, así fue en Tanzania, pues un director de proyecto de la RFA de la década de 1980 contó que médicos cubanos trabajaron en el hospital provincial, lo que "contribuyó a la alegría de nuestras mujeres". ${ }^{31}$ 
La verdad es que una regla superior para los cooperantes cubanos era el respecto de las costumbres locales, pero fue duro asimilar las costumbres de la vida etíope diferentes a las cubanas. Los cubanos encontraron un problema que confrontan todos los que trabajaban concretamente en una situación de desigualdad profunda. Desigualdad que se observó, por ejemplo, en la diferenciación del nivel material de vida - con tantas imágenes de niños hambrientos angolanos y etíopes en la memoria de los cubanos -, pero también por costumbres muy diversas: condiciones atrasadas, por ejemplo de higiene, en Angola, costumbres desconcertantes ante la muerte, que a primera vista resultaban incomprensibles para los cubanos que vivían en un mundo diferente (Hatzky, 2012: 302-305, 318-320).

Esas desigualdades ocasionaron elementos objetivos de separación de la población. El sentimiento de solidaridad coexistió con un sentimiento de profundas diferencias culturales. El "atraso cultural, la ignorancia técnica, el analfabetismo" calificó el jefe de la administración civil cubana en Angola, Jorge Risquet, como problemas mayores en el caso del pueblo angolano. ${ }^{32}$ Surgían sentimientos encontrados, por una parte la máxima de respetar lo diferente, lo desconocido dentro de esa sociedad; por otra parte, de dificultad para asimilar los comportamientos y costumbres de vida angolanos. El encuentro de una sociedad con grandes desigualdades provoca de forma casi inevitable la intención de querer cambiar o modificar la situación, de acuerdo con los patrones propios concebidos, hacia un estado diferente de cosas.

Desde las primeras instrucciones de las autoridades cubanas se trataba con respeto a la población africana. Aunque existían diferencias culturales, sociales y económicas evidentes, que para los cubanos quedaron saldadas en el pasado, superadas e impensables en la construcción del socialismo, de algún modo los cubanos provocaron un movimiento de la cosmovisión del continente africano. En ese sentido puede hablarse en términos educativos o de formación de cuadros y técnicos para sostener al Estado en las nuevas condiciones. Las transferencias son palpables con diferentes intensidades en el ámbito personal, grupal o nacional.

\section{LAS TRANSFERENCIAS}

E n general se efectuaron transferencias sistémicas: en términos del sistema educativo cubano (Hatzky 2012: parte II), de la cultura política, de la ideología y la conformación de la identidad nacional en Angola.

El MPLA envió a miles de niños y jóvenes a Cuba con el objetivo de formar un personal técnico y profesional para el nuevo Estado. Entonces Cuba concurrió esencialmente a la construcción de ese soporte técnico-profesional del aparato estatal en Angola. Además, Angola no era un país cohesionado; sino muy fragmentado en etnias que no compartían una identidad 
común. Con tantas diferencias internas, la Isla de la Juventud fue uno de los lugares en donde se fraguó un sentimiento de identidad unificada angolana. Allí llegaron angolanos de todos los territorios y allí se unieron y aprendieron las lenguas predominantes que fueron el español de Cuba y el portugués de Angola, aprendieron a unirse entre sí y a arraigar el sentido de pertenencia a un Estado común y comenzaron a casarse entre diferentes etnias. ${ }^{33}$

Aún más difícil de asimilar son las transferencias personales informales: costumbres, maneras de vivir y actitudes laborales. Los cubanos en Alemania aprendieron algunas virtudes de la "modernidad", según la revista del CECE Colaboración Internacional (1982: 26): "Hemos aprendido mucho en la RDA: disciplina en el estudio, cumplimiento de las normas y puntualidad en el trabajo", cuenta un cubano de su experiencia alemana. Enseñaron probablemente virtudes similares a los etíopes y angolanos. ${ }^{34}$ Los maestros cubanos en Angola transmitieron con su pedagogía comportamientos de regularidad en la atención en las clases, un cierto comportamiento controlado, normas de higiene, a sus alumnos angolanos (Hatzky, 2012: 278-279).

Según Pedro Ross, embajador cubano en Angola, otra transferencia importante se dio en las tradiciones. Actualmente muchos angolanos que estuvieron en Cuba se reúnen para jugar voleibol, escuchar música cubana, bailar casino, tomar cerveza y hablar español. Los estudiantes que fueron a Cuba se enorgullecen de ello y se refieren a los profesores y cubanos que los acogieron como sus "Mai" y "Pai" cubanos que los ayudaron durante los años no siempre fáciles que pasaron en Cuba. Existe también en Angola una Asociación de la Familia Cubano-Angolana, otra de cubanos que se han quedado en Angola a lo largo de los años. Muchos de los actuales ministros angolanos fueron formados en Cuba o tuvieron profesores cubanos, lo que se refleja incluso en su vocabulario. La presencia de Cuba ha tenido un impacto no solo en la preparación de miles de cuadros angolanos, sino en la cultura y en las artes de ese país.

\section{CONCLUSIÓN: ¿UN CICLO CUBANO DE INTERNACIONALISMO?}

E n términos de mutualidad, de reciprocidad, hay que preguntar por transferencias retroactivas sobre los cubanos en África. ¿Regresaron los internacionalistas cubanos marcados o hasta cambiados de su experiencia de terreno? ¿Hay un fondo de experiencia "internacionalista" común que distingue a los internacionalistas de otros cubanos sin esa experiencia?

La respuesta a esa pregunta queda tentativa. Es cierto que tuvieron experiencia de una vida no conocida, a veces muy difícil: situaciones atroces de guerra, de desigualdad, de privación, de separación por años de la familia, una realidad diferente de la cubana. Tuvieron que enfrentar situaciones de diferencia cultural, de nivel material de vida, de costumbres difíciles de asimilar. Eso los dispondría a capacidades internacionalistas en el sentido de un 
internacionalismo vivido, de una práctica internacionalizada como quedó esbozado a comienzos de esta investigación. Seguro que ese intercambio mundial - asesores y cooperantes de países socialistas europeos en Cuba, trabajadores cubanos en Europa, asesores y cooperantes cubanos en África, Asia y América Latina (aquí solamente hablamos de África, pero no hay que olvidar a Vietnam, Nicaragua, en ocasiones con 4.000 cooperantes después de Angola la segunda gran operación, y tantos otros), los hasta 25.000 a 40.000 estudiantes de esos países que se mezclaron en la Isla de la Juventud en $\mathrm{Cuba}_{1}{ }^{35}$ gran centro de formación de estudiantes de los tres continentes, gran experimento educativo que no puede ser sobreestimado, pero que todavía no ha encontrado un lugar correspondiente a su importancia en la historiografía.

Esa circulación de personas en los países socialistas y sus márgenes constituyó un eje internacional en que la Isla desempeñó un rol determinante para los países "subdesarrollados". En ese sentido, el internacionalismo, o, como lo llamaron observadores contemporáneos, el "globalismo cubano" 36 puede ser visto como una contribución cubana a la "globalización" del sistema socialista en las décadas de 1970 y 1980. Además, permitió a tantos cubanos conocer la experiencia de países no socialistas, de la que carecían la gran mayoría de los cubanos con la sola experiencia de vivir en la esfera bastante homogénea del Estado nacional cubano. El o la internacionalista tuvo más ocasiones de conocer otros lugares, otras situaciones, otras condiciones humanas, tuvo la posibilidad de vivir experiencias muy diversas, como las "mujeres sin fronteras" de Nancy Jiménez. El nivel de asimilación es otra pregunta. ¿Esa experiencia forjó un cuerpo de élite de internacionalistas de práctica?

No tenemos suficientes fuentes para responder de manera terminante esta pregunta. Presentamos una investigación en desarrollo, en progreso. ${ }^{37}$ De las entrevistas a internacionalistas en $\mathrm{Cuba}^{38}$ no surge la imagen de un sector marcado por una práctica de vida internacionalista, mundial como se esbozó en el inicio de este artículo; en su lugar, dominan experiencias de una misión o dos con el posterior regreso al país y la reinmersión en la vida regular cubana. Casi todos se ven marcados por esa experiencia de misión internacionalista. Igualmente se constata que el orgullo de haber cumplido una misión como representante de Cuba reforzó el sentimiento nacional cubano. Es cierto que abrió una ventana en el mundo en esa etapa, pero el internacionalismo como estilo de vida itinerante, como vocación de una vida entera, quedó reservado para unos pocos protagonistas del ciclo cubano de la revolución en los tres continentes.

Concluimos con la propuesta de distinguir un "ciclo cubano de revolución antiimperialista", es decir, un "ciclo cubano de desarrollo socialista" y un ciclo de inclusión de países periféricos de Asia, África y América Latina, por medio del "internacionalismo cubano", en los flujos de la historia mundial. 


\section{Notas}

1 Sigue Gleijeses (2013), con una amplia documentación de archivos cubanos, la gran mayoría de documentos reproducida en forma digital por el Wilson Digital Archive, pero enfocado sobre el aspecto militar. Piero Gleijeses tiene en sus libros sobre la participación cubana en Angola importantes momentos de esa historia. Mientras Gleijeses se enfoca en el lado militar, Hatzky (2012) recuerda la masiva asistencia civil cubana en Angola. Esos trabajos abren un nuevo ciclo de la historiografía después un ciclo dominado por trabajos provenientes de la emigración cubana a Estados Unidos.

2 Solo Cuba envió tropas, en el caso de la RDA solo se envió a personal especial de seguridad.

3 Educadores Cubanos. Calidad técnica y abnegación internacionalista, en Colaboración Internacional (1983).

4 "Indem wir Kuba helfen, Produktionskapazitäten aufzubauen, Importsubstitution, Stärkung Exportkraft, Erhöhung Nationaleinkommen, Entwicklung Sozialismus, versetzen wir Kuba auch in die Lage, durch Exporte Verpflichtungen gegenüber der DDR zu erfüllen" "Arbeitsentschließung der GO Havanna, 12.11.1988, Bundesarchiv Berlin (BA), SAPMO, DY 30/14442.

5 La idea está presente en Sergio Roca (1982: 168-170), Michael Erisman (1985), y es una idea central en Sergio Díaz-Briquets (ed., 1989).

6 Desde la perspectiva de los documentos de la RDA en acuerdo con la visión soviética se percibía una situación económica desfavorable en Cuba a principios de la década de 1970, representada en el fracaso de la Gran Zafra y la autocrítica siguiente de Fidel, ciclo de desarrollo autónomo que finalizó con la entrada al CAME en 1972 con la finalidad de integrarse en el sistema de división del trabajo socialista mundial, intervención masiva de ayuda material y asesores/cooperantes de parte de la URSS, la RDA y otros países socialistas, establecimiento de planificación central; $y$ en esa coyuntura el auge de un nuevo tipo y envergadura de "internacionalismo cubano", informes y análisis del "Grupo de trabajo CAME" (Arbeitsgruppe RGW) del CC del SED, BA Berlin, DY 30/27030-27033.

7 Comentario de las palabras de Fidel: "Ser internacionalista es saldar nuestra deuda con la humanidad" en el último número de Colaboración Internacional (1990: 38).

8 HPA Addis Ababa, Zu wesentlichen Fragen der Außenhandelsbeziehungen Äthiopiens, Addis Ababa 4.10.1978, BA Berlin, DL 226/49, fol. 350

9 Bohemia, 22.12.1978; Díaz-Briquets y Pérez-López (1989: 52-53), citando un discurso de Fidel Castro de dec. 1977 in Granma Weekly Review, 15.1.1978; cf. Memorandum of Conversation Fidel Castro/Agostinho Neto 26.1.1979, cit. en Gleijeses (2013: 82-84).

10 Según un informe de la sección económica de la embajada RDA en Cuba, Angola pagó parte de los gastos para los expertos cubanos con 3000t de café: Botschaft der DDR/Leiter der WPA Salzmann, Kurzinformation über die wirtschaftlichen und wissenschaftlich-technischen Beziehungen Kubas zu Angola, Mocambique und Libyen, Havanna 6.3.1979, BA Berlin, SAPMO DY 30/27032.

11 Memorandum of Conversation between Fidel Castro and Agostinho Neto, 26.1.1979, Wilson Digital Archive, http://digitalarchive.wilsoncenter.org/document/117941, p.38-39 (20.6.2016).

12 Idem, p.40-42 (cita).

13 Acuerdo Especial, 5.11.1977, Wilson Digital Archive, http://digitalarchive.wilsoncenter.org/document/117931 (19.2.2015). 
14 José Eduardo dos Santos a Fidel Castro, 28.10.1983, Wilson Digital Archive, http://digitalarchive.wilsoncenter.org/document/117979 (19.2.2015); Gleijeses (2013: 229, 240).

15 Entrevista con Noemí Benítez de Mendoza, La Habana 13.3.2015. Los archivos del CECE que Gleijeses encontró a principios de la década de 2000 en el MINCEX hoy ya no se encuentran.

16 Etiopía: MINREX, Dirección de África Subsahariana, Memorandum a Viceministro Gerardo Mazola: Informe del cumplimiento del plan de trabajo de preparación del cro. Fernando Prats Mari, consejero en Etiopía, 10.6.1986, Archivos MINREX, Caja Etiopía; Angola: Agreements signed between Cuba and Angola in 1976 (extracts), in Nazario/ Benemelis (1989: 27-28).

17 Entrevista a Antonio Pérez, La Habana 12.8.15.

18 Según un alto funcionario del Partido, la iniciativa vino de Lamberz quien realizó una escala espontánea en Etiopía durante su regreso desde Mozambique en marzo 1977. Entrevista a Friedel Trappen, en Döring (1999: 111).

19 BA Berlin, SAPMO IV 2/2.033/120; Gleijeses (2013: 45-46); para esa secuencia cf. también los documentos provenientes de archivos soviéticos y cubanos publicados en: http://digitalarchive.wilsoncenter.org/ collection/42/horn-of-africa-crisis (19.2.2015).

20 Oberstleutnant Mengistu Haile Mariam to Genossen Honecker, Addis Ababa 9.3.1977, BA Berlin SAPMO DY 30/IV 2/2.033/87, fol. 17-27.

21 Telegram Stelzer, Addis Ababa 21.3.1977 concernante Castro-Mengistu, BA Berlin, SAPMO IV 2/2.033/119, fol. 11; Gleijeses (2013: 46).

22 Síntestis analítica sobre la situación en Etiopía. Proposiciones, marzo 1977, Wilson Digital Archive, http:// digitalarchive.wilsoncenter.org/collection/42/horn-of-africa-crisis/document/117924 (19.2.2015).

23 Entrevista a Dieter Klinkert, Berlin 21.2.2015.

24 Roca (1982: 163b), citando Cuba Internacional (julio 1978: 67).

25 Roca (1982), citando Granma (5.11.1979).

26 Bericht über den Stand der Realisierung der DDR-Vorhaben Zementfabrik New Mugher, Textilkombinat Kombolcha und des langfristigen Importabkommens mit dem Sozialistischen Äthiopien, Berlin 13.6.1983, BA Berlin, DL 226/50; Cuba-Etiopía, Colaboración Internacional (1/1980); Unfried (2016: 31); Díaz-Briquets y Pérez-López (1989: 77) indican, con base en fuentes cubanas, una cifra de 400 trabajadores cubanos que es el doble de la cifra proveniente de las fuentes alemanes.

27 Ejemplos en Unfried (2014: 384-385).

28 Entrevista a Antonio Pérez, La Habana, 12.8.2015.

29 Entrevista a Manuel Normando Agramonte, La Habana, 21.7.2015.

30 Entrevista a Antonio Pérez, La Habana, 12.8.2015.

31 Entrevista a Harald Esche, Berlin 8.11.2014.

32 Zusammenfassung einer Rede von Jorge Risquet, Mitglied des Sekretariats des ZK der KP Kubas, gehalten zum Abschluss der II. Konferenz der Parteiorganisation der Zivilen Kubanischen Mission in der VR Angola, 
10.10.1976, BA Berlin DY 30/27031 (die kulturelle Rückständigkeit, "die technische Unwissenheit, das Analphabetentum").

33 Entrevista a Pedro Ross, La Habana, 22.7.2015.

34 En la Isla de la Juventud "se observa disciplina, limpieza y un gran entusiasmo" (Colaboración Internacional, 1982: 39).

35 Las cifras se recogieron de los documentos históricos del departamento de becas del MINREX, Archivos MINREX, La Habana. Quizás la cifra superior se refiera a estudiantes extranjeros en el país entero.

36 "Cuban globalism" es una noción usada a menudo en Erisman (1985).

37 En el ramo del proyecto de investigación histórica "Experts in 'Development' and 'Socialist Aid' in the Era of Global Competition between the Political Systems of the 'West' and 'East'", financiado por Austrian Science Fund (FWF).

3833 entrevistas autobiográficas efectuadas en La Habana entre marzo del 2015 y mayo del 2016.

\section{REFERÊNCIAS BIBLIOGRÁFICAS}

\section{REVISTAS}

Bohemia, La Habana, 1978.

Colaboración Internacional: Revista del Comité Estatal de Colaboración Económica, La Habana, 1980-1990.

\section{MONOGRAFÍAS y ARTíCUlOS}

DÍAZ-BRIQUETS, Sergio (ed.). Cuban internationalism in Sub-Saharan Africa. Pittsburgh: Duquesne University Press, 1989.

\& PÉREZ LÓPEZ. Internationalist civilian assistance: the Cuban presence in Sub-Saharan Africa. In: DÍAZ-BRIQUETS, Sergio (ed.). Cuban internationalism in Sub-Saharan Africa. Pittsburgh: Duquesne University Press, 1989, p. 48-77.

DOMÍNGUEZ, Jorge I. To make a world safe for revolution. Cuba's Foreign Policy. Massachusetts: Harvard University Press, 1989.

DÖRING, Hans-Joachim. Es geht um unsere Existenz. Die Politik der DDR gegenüber der Dritten Welt am Beispiel von Mosambik und Äthiopien. Berlin: Ch. Links, 1999.

ERISMAN, H. Michael. Cuba's international relations. The anatomy of a nationalistic foreign policy, Foreign Affairs, 86, 1985.

Cuban development aid: South-South diversification and counterdependency politics. In \& KIRK, John M. (eds.). Cuban foreign policy confronts a new international order. Boulder: Lynne Rienner, 1991, p. 139-165. 
FEINSILVER, Julie. Fifty years of Cuba's medical diplomacy: from idealism to pragmatism, Cuban Studies, 41, 2010, p. 85-104.

GARCÍA MÁRQUEZ, Gabriel. Operación Carlota: Ios Cubanos en Angola. Lima: Mosca Azul, 1977.

GLEIJESES, Piero. Moscow's Proxy? Cuba and Africa 1975-1988, Journal of Cold War Studies, 4, 2006, p. 3-51.

Visions of freedom. Havana, Washington, Pretoria, and the struggle for Southern Africa, 1976-1991. Chapel Hill: University of California Press, 2013.

HATZKY, Christine. Kubaner in Angola. Süd-Süd-Kooperation und Bildungstransfer 1976-1991. München: De Gruyter Oldenbourg, 2012.

MARTÍN GONZÁLEZ, Isabel. Angola en la memoria y en el corazón, manuscrito, 2015.

NAZARIO, Olga \& BENEMELIS, Juan. Cuba's relations with Africa. In: DÍAZ-BRIQUETS, Sergio (ed.). Cuban internationalism in Sub-Saharan Africa. Pittsburgh: Duquesne University Press, 1989.

RAMONET, Ignacio. Cien horas con Fidel: conversaciones con Ignacio Ramonet. 3a ed. La Habana: Oficina de Publicaciones del Consejo de Estado, 2006.

ROCA, Sergio. Economic aspects of cuban involvement in Africa. In: MESA-LAGO, Carmelo \& BELKIN, June S. (eds.). Cuba in Africa. Pittsburgh: University of Pittsburgh, 1982.

UNFRIED, Berthold. Instrumente und Praktiken von "Solidarität" Ost und "Entwicklungshilfe" West: Blickpunkt auf das entsandte Personal. In:_— \& HIMMELSTOSS, Eva (eds.) Praktiken von Internationaler Solidarität und Internationaler Entwicklung. Leipzig: [s. n.], 2012, p. 73-98.

Scènes de la vie quotidienne des coopérants de la RDA en Afrique: normes de comportement et transgressions. In: Coopérants et coopération en Afrique: circulations d'acteurs et recompositions culturelles, dossier thématique Outre-Mers, Révue d'Histoire, 2014.

—. Friendship and education, coffee and weapons. Exchanges between socialist Ethiopia and the German Democratic Republic, Northeast African Studies, 2016, 1, p. 15-38. 
